\title{
Successful reconstitution of leukocyte adhesion defect after umbilical cord blood stem cell transplant
}

\author{
SUSHMITA CHAKRABORTY ${ }^{1}$, DEVIKA GUPTA ${ }^{1}$, DEEPSHI THAKRAL ${ }^{1}$, SAMEER BAKHSHI , \\ PRABIN KUMAR ${ }^{l}$, SUSHIL KUMAR KABRA ${ }^{3}$, RAKESH LODHA ${ }^{3}$, DIPENDRA KUMAR MITRA ${ }^{l}$
}

${ }^{1}$ Department of Transplant Immunology and Immunogenetics, All India Institute of Medical Sciences, New Delhi, India

${ }^{2}$ Department of Medical Oncology, All India Institute of Medical Sciences, New Delhi, India

${ }^{3}$ Department of Pediatrics, All India Institute of Medical Sciences, New Delhi, India

\begin{abstract}
Leukocyte adhesion deficiencies (LADs) are a type of primary immunodeficiencies characterized by delayed detachment of the umbilical cord, impaired wound healing, leukocytosis, and recurrent infections. The disease is caused by genetic defects affecting different steps in the process of leukocyte adhesion cascade such as rolling, integrin activation, and adhesion of leukocytes, resulting in the impairment of leukocyte trafficking. Till date, three types of LAD have been documented: type I, II and III. Type I LAD is caused by congenital defect in the $\beta 2$ integrin receptor complex CD11/CD18 on the cell surface of leukocytes, which results in impaired leukocytes connection to endothelial cells and migration. Type II LAD is caused by defect in the fucose metabolism resulting in the absence of fucosylated selectin ligands on neutrophils and impaired rolling phase of the leukocyte adhesion cascade. Type III LAD is caused by mutations in the kindlin-3 gene resulting in defective integrin activation. In this article, we present a review of literature for type I LAD, and successful treatment of patient using umbilical cord blood stem cell transplantation.
\end{abstract}

Key words: primary immunodeficiency, leucocyte adhesion defect, immune trafficking, umbilical cord, stem cell transplant.

(Centr Eur J Immunol 2020; 45 (1): 117-121)

\section{Introduction}

Leukocyte adhesion deficiencies (LADs) are a group of primary immunodeficiencies, in which leukocytes, primarily polymorphonuclear leukocytes (PMNs, neutrophils), and monocytes are unable to traffic [1]. Leukocyte trafficking is a dynamic process and involves highly regulated multi-step cascades of interaction between adhesion molecules on leukocytes and endothelium [2]. This process is critical for leukocyte extravasation from blood to the sites of inflammation, infection, tissue injury, and for the continuous surveillance of non-self antigens. Impaired leukocyte trafficking in LAD is due to the genetic defect in expression or activation of adhesion molecules. Till date, three types of LAD have been described: type I, II, and III, of which type I is the commonest [3]. Type I LAD results from a congenital defect in the $\beta 2$ integrin receptor complex CD11/CD18 on the cell surface of leukocytes. The disease is characterized by delayed separation of the umbilical cord at birth, high frequency of omphalitis, recurrent fungal or bacterial infections of skin and mucosa, defect in pus formation and wound healing, marked polymorphonuclear leukocytosis with a neutrophil count ranging from 12,000 to 100,000 cells $/ \mathrm{mm}^{3}$, chronic periodontitis, and gingivitis in the adulthood. Type II LAD is very rare form of LAD and is caused by the defect in fucose metabolism resulting in absence of sialyl Lewis X (SLex, CD15s), a fucose-containing glycoconjugate ligand and other fucosylated selectin ligands on neutrophils. Binding of fucosylated selectin ligands to E (CD62E), P (CD62P), and $\mathrm{L}(\mathrm{CD} 62 \mathrm{~L})$ selectins on the activated endothelium is essential for the rolling phase of adhesion, and this phase is defective in LAD II patients. Fever, leukocytosis, presence of Bombay blood group, growth, and psychomotor retardation are some of the distinct clinical features of LAD II patients. Compared to type I and II, type III LAD has been recently described, and is caused by mutation within the FERMT3 gene, which prevents the expression of kindlin-3, a protein expressed by hematopoietic cells, and is important for the regulation of integrin activation. Due to the defect in activation of integrins, LAD III patients

Correspondence: Prof. Dipendra Kumar Mitra, Department of Transplant Immunology and Immunogenetics, All India Institute of Medical Sciences, 110029 New Delhi, India, e-mail: salilmitra2@gmail.com Submitted: 15.12.2017; Accepted: 5.03.2018 
display abnormal adhesion and migration of leukocytes, platelet aggregation, and osteoclast functions.

In this report, we present a case of LAD I, who was successfully transplanted with cord blood hematopoietic stem cell at our center, achieving normalization of his immune deficiency.

\section{Case report}

A two-and-a-half years old child was born at term, out of non-consanguineous marriage to a primigravidae, by normal delivery. The child was apparently asymptomatic till 18 days of life, when he developed fever following BCG vaccination, and was treated with intravenous antibiotics to which he responded. The umbilical cord separation of the child was on day 18. At two months of age, he had repeated episodes of fever associated with vomiting and left otitis externa. The child was managed conservatively; however, he continued to have recurrent episodes of fever requiring hospitalization. The child had no history of skin infection, gingivitis, or periodontitis. Laboratory investigations revealed a hemo- globin level of $11.2 \mathrm{~g} / \mathrm{dl}$, high total leucocyte count (TLC) of $25,200 / \mathrm{mm}^{3}$ with absolute neutrophil count of $22,680 / \mu \mathrm{l}$ (normal range, 1.5-8.5 × 10\% $/$ ), and absolute lymphocyte

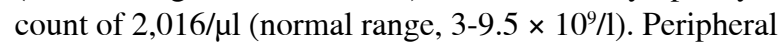
blood examination was suggestive of polymorphonuclear leukocytosis, with mild left shift and toxic granules. The other hematological and biochemical parameters were normal. Serological tests, which were performed for any infectious etiology including Widal, HIV, anti-HBsAg, anti-HCV, dengue, brucella, EBV, and leptospira were all negative. Additionally, the blood and urine culture did not grow any organism. The child at nine months of age underwent a high resolution computed tomography (HRCT) of head for otitis media, which showed a lobulated soft tissue structure measuring $19.3 \times 18.2 \mathrm{~mm}$, suggesting erosion along the inferior aspect of the mastoid and extending up to the tympanic membrane. Magnetic resonance imaging (MRI) revealed an ill-defined area of soft tissue measuring $7.3 \times 11 \times 6.2 \mathrm{~mm}$ adjacent to left temporal bone, extending to lateral margin suggestive of otitis externa. The lesion appeared ulcerated near osseous portion of ex-

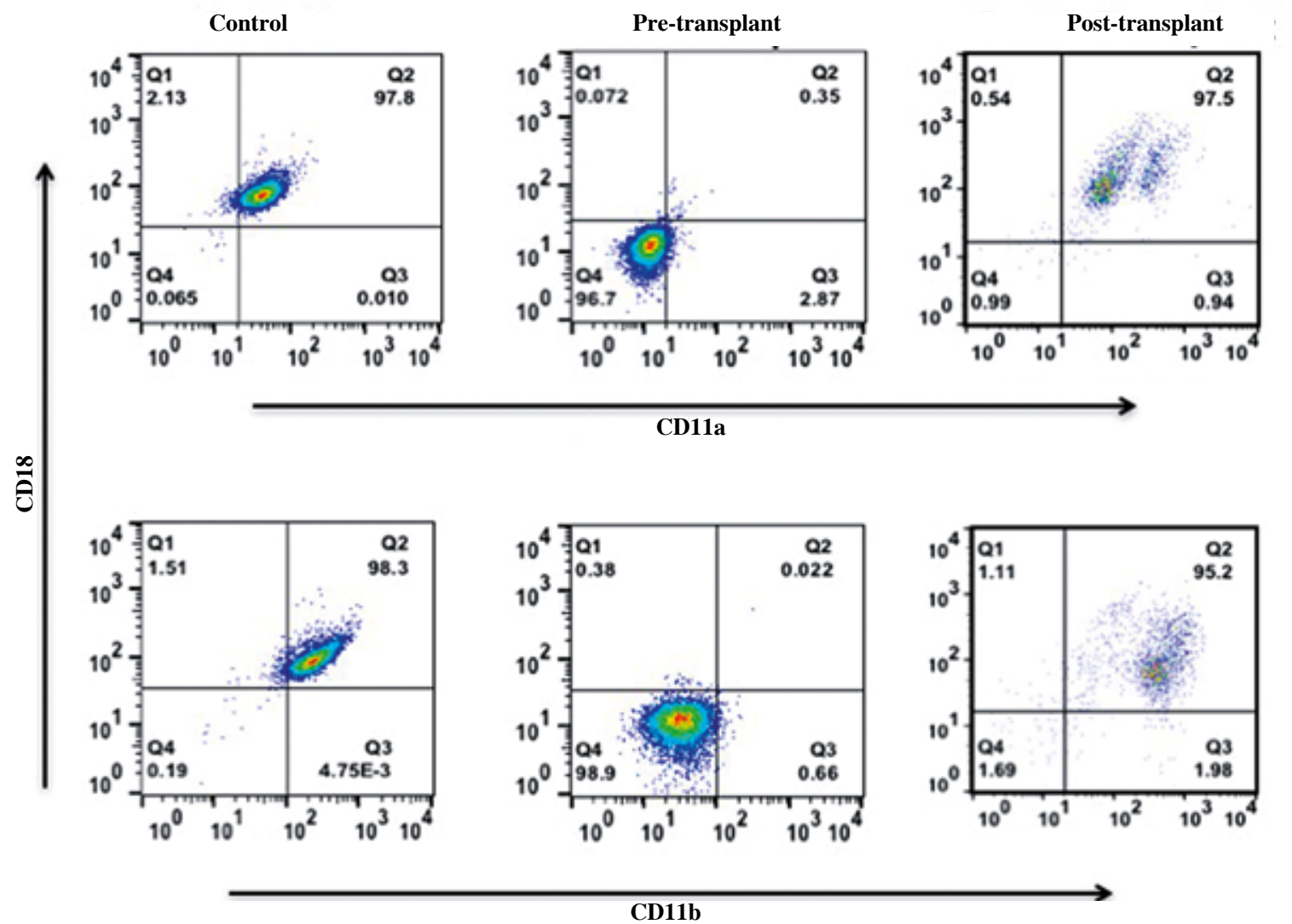

Fig. 1. Expression of CD11a/CD18 and CD11b/CD18. Peripheral blood mononuclear cells were obtained from whole blood. Cells were stained ex vivo for surface markers, with fluorescently conjugated anti-CD18 PE and anti-CD11a FITC and CD11b PECy5. Samples were acquired with BD FACS Calibur and analyzed using FlowJo software v. 9.810.2. For data analysis, granulocytes were gated on Forward scatter and Side scatter, and cells were checked for the expression of CD11a/CD18 and CD11b/CD18 
ternal auditory canal, associated with swelling and erythema. Tissue biopsy from left ear showed large areas of necrotic tissue with evidence of fat necrosis. Based on these clinical and laboratory findings, a provisional diagnosis of primary immunodeficiency was considered.

Primary immunodeficiency screening workup was performed for the child in our laboratory using flow cytometry, which showed normal $\mathrm{T}\left(\mathrm{CD}^{+}\right), \mathrm{B}\left(\mathrm{CD} 19^{+}\right)$, and $\mathrm{NK}\left(\mathrm{CD} 3^{-}, \mathrm{CD}^{\circ} 6^{+}\right)$cell frequency with $\mathrm{CD} 4$ : CD8 ratio greater than 1.5. The neutrophil oxidative index value of DHR (dihydrorhodamine) assay performed for chronic granulomatous disease was within normal range. However, the LAD I analysis showed markedly reduced surface expression of CD11a/CD18 and CD11b/CD18 markers on gated granulocytes as compared to age-matched healthy control. The frequency of granulocytes having dual expression of CD11a/CD18 and CD11b/CD18 was below $1 \%$ (Fig. 1). Based on the results of immunological evaluation, the presence of leukocytosis with neutrophilia, and recurrent infections with persistent otitis media, a definitive diagnosis of LAD I was established.

The patient was taken up for matched unrelated umbilical cord blood stem cell transplant, following an extensive pretransplant clinical, laboratory, and radiological workup. He was given non-myeloablative conditioning regimen, with intravenous fludarabine of $30 \mathrm{mg} / \mathrm{m}^{2}$ (total dose, $150 \times 0.45=$ $67.5 \mathrm{mg}$ ) on day -7 and day -4 , melphalan of $70 \mathrm{mg} / \mathrm{m}^{2}$ on day -3 and day -2 (total dose, $140 \times 0.45=63 \mathrm{mg}$ ), and anti-thymocyte globulin (ATG) of $10 \mathrm{mg} / \mathrm{kg}$ on day -4 to day -1 (total dose, $10 \times 10 \times 4=400 \mathrm{mg}$ ) [4]. Post-transplant, the child was placed on GVHD prophylaxis with cyclosporine of $1.5 \mathrm{mg} / \mathrm{kg}$ i.v. BD from day -1 and mycophenolate mofetil - $30 \mathrm{mg} / \mathrm{kg} / \mathrm{D}$ in two divided doses w.e.f. D+1. Patient developed febrile neutropenia on day -4 along with grade 2 diarrhea. He was managed with intravenous meropenam, caspofungin, and metronidazole to which he responded. Supportive treatment with antibiotic/antifungal and antiviral prophylaxis was continued. He achieved neutrophil engraftment on D+47 and platelet engraftment on D+48. Presently, the child is healthy at two years post-transplant, and all his laboratory parameters including CD11a/CD18 and CD11b/ CD18 expression on granulocytes have normalized (Fig. 1).

\section{Discussion}

LAD is a type of immunodeficiency, characterized by the defect in the process of leukocyte adhesion cascade, which includes multiple regulated steps such as rolling, integrin activation, and adhesion of leukocytes. The disease has been categorized into three types, which are summarized in Table 1.

LAD I is a rare autosomal recessive disorder caused by heterogeneous germ-line mutations of CD18 gene located on the long arm of human chromosome $21 \mathrm{q} 22.3$, which encodes the $\beta$ subunit of $\beta 2$ integrins family [5]. More than 300 cases of LAD I have been documented worldwide and have a very heterogenous molecular nature. A variety of mutations have been observed in patients with LAD I in

Table 1. An overview of the diagnosis, treatment, clinical, and molecular features of the three types of Leukocyte adhesion deficiency (LAD)

\begin{tabular}{|c|c|c|c|}
\hline Feature & LAD type I & LAD type II & LAD type III \\
\hline Clinical features & $\begin{array}{l}\text { Delayed detachment of umbilical } \\
\text { cord, leukocytosis, recurrent } \\
\text { infections, chronic periodontitis, } \\
\text { gingivitis, impaired pus formation } \\
\text { and wound healing }\end{array}$ & $\begin{array}{c}\text { Delayed detachment of umbilical cord, } \\
\text { leukocytosis, recurrent infection, severe } \\
\text { mental and growth retardation, rare and } \\
\text { other neurological manifestations, facial } \\
\text { and skeletal abnormalities, rare Bombay } \\
\text { phenotype }\end{array}$ & $\begin{array}{l}\text { Delayed detachment of umbilical } \\
\text { cord, leukocytosis, recurrent infection, } \\
\text { increased bleeding tendency due to } \\
\text { dysfunctional platelet aggregation, as } \\
\text { in Glanzmann's thrombasthenia }\end{array}$ \\
\hline $\begin{array}{l}\text { Diagnosis by } \\
\text { flow cytometry }\end{array}$ & $\begin{array}{l}\text { Reduced or absence of the } \\
\text { expression of } \beta 2 \text { integrins CD11a/ } \\
\text { CD18, CDI1 b/CD18, CD11d/ } \\
\text { CD18, and CD11c/CD18 on } \\
\text { myeloid leukocytes }\end{array}$ & $\begin{array}{c}\text { Absence of sialyl Lewis X expression on } \\
\text { neutrophil }\end{array}$ & $\begin{array}{l}\text { Reduced expression or absence of } \\
\text { kindlin-3 in leukocytes }\end{array}$ \\
\hline Mutation locus & ITGB2 at $21 \mathrm{q} 22.3$ & SLC $35 \mathrm{CI}$ at $11 \mathrm{p} 11.2$ & FERMT3 at $11 \mathrm{q} 13.1$ \\
\hline Genetic defects & $\begin{array}{l}\text { Defect in expression of } \beta 2 \text { integrin } \\
(\alpha 1 \beta 2, \alpha \mathrm{M} \beta 2, \alpha \mathrm{X} \beta 2 \text {, and } \alpha \mathrm{D} \beta 2)\end{array}$ & $\begin{array}{l}\text { Defect in fucosylation of various cell } \\
\text { surface glycoproteins }\end{array}$ & $\begin{array}{c}\text { Defect in activation of } \beta 1, \beta 2 \text {, and } \beta 3 \\
\text { integrin on leukocytes and platelets }\end{array}$ \\
\hline $\begin{array}{l}\text { Functional } \\
\text { defects }\end{array}$ & $\begin{array}{l}\text { Adhesion and transendothelial } \\
\text { migration of leukocytes }\end{array}$ & "Rolling" of leukocytes & $\begin{array}{l}\text { Adhesion and transendothelial } \\
\text { migration of leukocytes, platelet } \\
\text { aggregation, osteoclast function }\end{array}$ \\
\hline Treatment & $\begin{array}{l}\text { Antibiotic prophylaxis, white } \\
\text { blood cell (granulocyte) } \\
\text { transfusions and hematopoietic } \\
\text { stem cell transplantation (HSCT) }\end{array}$ & $\begin{array}{l}\text { Fucose supplementation, treatment with } \\
\text { antibiotics in case of acute infection }\end{array}$ & $\begin{array}{l}\text { Blood transfusion during bleeding } \\
\text { episodes, treatment with antibiotics in } \\
\text { case of acute infection, granulocyte } \\
\text { transfusions, and HSCT }\end{array}$ \\
\hline
\end{tabular}


the CD18 gene, which includes point mutation, splicing defects, deletions, insertion, nonsense, and missense mutations [6]. These mutations result in abnormalities in CD18 protein, which ranges from absence or reduced expression to truncated or unstable protein product formation. Among all the mutations known in CD18 gene, there is a S138P mutation that permits CD11/CD18 expression, but impairs function [7]. Mutations in CD18 interfere with the CD11/ CD18 interaction and cause diminished levels of expression of the four integrins on myeloid leukocytes, namely lymphocyte function antigen-1 (LFA-1, CD11a/CD18), Mac-1 (CD11b/CD18), Gp 150/95 (CD11c/CD18), and $\alpha_{\mathrm{D}} \beta_{2}(\mathrm{CD} 11 \mathrm{~d} / \mathrm{CD} 18)$ [8-11].

Expression of the CD11/CD18 complex on the leukocytes is essential for various activities of leukocyte such as phagocytosis, cell-mediated cytotoxicity, adhesion, and transendothelial migration. In LAD I patients, defect in leukocyte adhesion and migration due to these integrins results in the clinical features, which include susceptibility to recurrent bacterial and fungal infections, elevation of neutrophil counts in the blood during infection, absence of pus at the sites of infection, dystrophic scars from skin injuries, severe gingivitis, and periodontitis [8, 12]. In most cases, the severity of the disease directly correlates with the level of expression of the CD11/CD18 antigens [13]. LAD I patients, categorized as having severe clinical phenotype, would have less than $2 \%$ of the normal expression of CD18 and are highly susceptible to systemic infections, which can lead to death in childhood if proper therapeutic intervention is not provided. LAD I patients expressing CD18, which ranges from 2 to $30 \%$ of the normal level, would be affected by mild to moderate clinical phenotype and can live to adulthood with careful management, but experiences severe periodontitis, tooth loss, and defect in tissue remodeling of infected sites and wounds. In our patient, the surface expression of CD11a/CD18 and CD11b/CD18 markers on granulocytes was $<1 \%$, associated with severe clinical phenotype.

Disease management depends on the clinical severity. Patients categorized with mild to moderate phenotype are managed with appropriate antibiotics during infection, and by improving oral hygiene in order to prevent periodontitis. However, the only available treatment option for patients with severe LAD I clinical phenotype is hematopoietic stem cell transplantation (HSCT), which has good outcome as was seen in our patient $[14,15]$. Recently, Moutsopoulos et al. have reported a successfully disease management of one LAD I patient with ustekinumab, an antibody that blocks the activity of interleukin 23/interleukin 12 and inhibits the production of interleukin 17 $[16,17]$. The authors have observed resolution of refractory oral inflammation and healing of a severe sacral wound in the LAD patient with ustekinumab treatment. However, treatment of more LAD I patients with this biologic therapy is extremely necessary to understand its use in the disease management.
Here, we wanted to highlight that increased awareness of this rare primary immunodeficiency disease amongst clinicians and availability of simple, robust flow cytometry-based immunological laboratory facilities can help to confirm the diagnosis early in life and prevent fatal complications. Our patient is presently disease-free after HSCT and is on regular follow-up at medical oncology out-patient department (OPD).

\section{Conclusions}

LAD I is a rare autosomal recessive primary immunodeficiency disorder caused by mutations in the $\beta$ subunit of CD18, which manifest in early neonatal period with life-threatening clinical features. Diagnosis often gets delayed because of lack of awareness and specialized laboratory facilities for flow cytometry and genetic studies. Timely diagnosis can prevent from devastating complications affecting patient's life and can help to plan for HSCT, which is the only potential curative treatment option.

\section{The authors declare no conflict of interest.}

\section{References}

1. Etzioni A, Harlan JM (2007): Cell adhesion and leukocyte adhesion defects. In: Ochs HD, Smith CIE, Puck JM, editors. Primary immunodeficiency diseases. 2nd ed. Oxford: 550-561.

2. Vestweber D (2007): Adhesion and signaling molecules controlling the transmigration of leukocytes through endothelium. Immunol Rev 218: 178-196.

3. Hanna S, Etzioni A (2012): Leukocyte adhesion deficiencies. Ann N Y Acad Sci 1250: 50-55.

4. Hamidieh AA, Pourpak Z, Hosseinzadeh M, et al. (2012): Reduced-intensity conditioning hematopoietic SCT for pediatric patients with LAD-1: clinical efficacy and importance of chimerism. Bone Marrow Transplant 47: 646-650.

5. Anderson DC, Springer TA (1987): Leukocyte adhesion deficiency: an inherited defect in the Mac-1, LFA-1, and p150,95 glycoproteins. Annu Rev Med 38: 175-194.

6. van de Vijver E, Maddalena A, Sanal Ö, et al. (2012): Hematologically important mutations: leukocyte adhesion deficiency (first update). Blood Cells Mol Dis 48: 53-61.

7. Hogg N, Stewart MP, Scarth SL, et al. (1999): A novel leukocyte adhesion deficiency caused by expressed but nonfunctional beta2 integrins Mac 1 and LFA-1. J Clin Invest 103: 97-106.

8. Etzioni A (2010): Defects in the leukocyte adhesion cascade. Clin Rev Allergy Immunol 38: 54-60.

9. Bunting M, Harris ES, McIntyre TM, et al. (2002): Leukocyte adhesion deficiency syndromes: adhesion and tethering defects involving beta 2 integrins and selectin ligands. Curr Opin Hematol 9: 30-35.

10. Harris ES, Weyrich AS, Zimmerman GA (2013): Lessons from rare maladies: leukocyte adhesion deficiency syndromes. Curr Opin Hematol 20: 16-25.

11. Shaw JM, Al-Shamkhani A, Boxer LA, et al. (2001): Characterization of four CD18 mutants in leucocyte adhesion deficient (LAD) patients with differential capacities to support 
expression and function of the CD11/CD18 integrins LFA-1, Mac-1 and p150,95. Clin Exp Immunol 126: 311-318.

12. Fiorini M, Vermi W, Facchetti F, et al. (2002): Defective migration of monocyte-derived dendritic cells in LAD-1 immunodeficiency. J Leukoc Biol 72: 650-666.

13. Etzioni A (2009): Genetic etiologies of leukocyte adhesion defects. Curr Opin Immunol 21: 481-486.

14. Al-Dhekri H, Al-Mousa H, Ayas M, et al. (2011): Allogeneic hematopoietic stem cell transplantation in leukocyte adhesion deficiency type 1: a single center experience. Biol Blood Marrow Transplant 17: 1245-1249.

15. Qasim W, Cavazzana-Calvo M, Davies EG, et al. (2009): Allogeneic hematopoietic stem-cell transplantation for leukocyte adhesion deficiency. Pediatrics 123: 836-840.

16. Moutsopoulos NM, Zerbe CS, Wild T, et al. (2017): Interleukin-12 and Interleukin-23 Blockade in Leukocyte Adhesion Deficiency Type 1. N Engl J Med 376: 1141-1146.

17. Hajishengallis G, Moutsopoulos NM (2014): Etiology of leukocyte adhesion deficiency-associated periodontitis revisited: not a raging infection but a raging inflammatory response. Expert Rev Clin Immunol 10: 973-975. 